\title{
Isolation and radiation hybrid mapping of a highly polymorphic CA repeat sequence at the SREBP cleavage-activating protein (SCAP) locus
}

\begin{abstract}
Sterol regulatory element binding protein (SREBP) cleavage-activating protein (SCAP) is a central regulator of lipid synthesis and uptake in animal cells. A polymorphic dinucleotide (CA) repeat sequence was isolated from a genomic clone containing the SCAP gene and was mapped to chromosome $3 \mathrm{p} 21.3$. High heterozygosity (0.89) makes this polymorphism a useful marker in the genetic study of disorders affecting lipid metabolism.
\end{abstract}

Key words SREBP cleavage-activating protein (SCAP) · Dinucleotide repeat $\cdot$ Lipid metabolism

\section{Introduction}

Sterol regulatory element binding protein (SREBP) cleavage-activating protein (SCAP) is a central regulator of lipid synthesis and uptake in animal cells (Hua et al. 1996; Brown and Goldstein 1997). Located in the endoplasmic reticulum, SCAP stimulates the proteolytic cleavage of SREBPs that activate the synthesis of cholesterol and unsaturated fatty acids and their uptake from plasma via the low-density lipoprotein (LDL) receptor. SCAP-stimulated proteolysis releases active fragments of SREBPs from membranes of the endoplasmic reticulum and allows them to enter the nucleus, where they activate transcription. The activity of SCAP is abolished by sterols, a regulatory mechanism that maintains the constant lipid composition of cell membranes.

T. Nakajima $\cdot$ N. Ota $\cdot$ M. Emi $(\square)$

Department of Molecular Biology, Institute of Gerontology, Nippon Medical School, 1-396 Kosugi-cho, Nakahara-ku, Kawasaki 211-8533, Japan

Tel. +81-44-733-5230; Fax +81-44-733-5192

e-mail: memi@nms.ac.jp

T. Kodama

RCAST, University of Tokyo, Tokyo, Japan
Point mutations in the sterol-sensing domain of SCAP cause resistance to sterol suppression (Hua et al. 1996; Nohturfft et al. 1998). Cells with a point mutation continue to synthesize cholesterol and to take up LDL even when they are massively overloaded with sterols. In transgenic mice that expressed mutant SCAP in liver, the result was enlarged livers that were engorged with cholesterol and triglycerides (Korn et al. 1998).

Given the central role of SCAP in the regulation of lipid metabolism, molecular variants in the human SCAP gene would likely result in alterations in plasma lipoprotein levels and/or derangement of lipid metabolism within tissues. As a first step in determining whether molecular variants in the $S C A P$ gene contribute to human disease, we isolated a highly polymorphic dinucleotide repeat at this locus.

\section{Source/Isolation of CA repeat sequence}

A bacteriophage P1 library (Genome Systems, St. Louis, MO, USA) was screened by the polymerase chain reaction (PCR), using two oppositely oriented oligonucleotides (forward: 5'-TGGGGATGTCACCTCCCTTAC-3' and reverse: 5'-TGCTGAATGGAGTAGAACTTGATGC-3') that correspond to nucleotide positions 3476-3495 and 3564-3588 of human SCAP cDNA (KIAA0199; GenBank Accession no. D83782) (Nagase et al. 1996). A fragment containing the CA repeat was identified by Southern blotting of PAC DNA digested by HaeIII, Sau3A, or RsaI with the $(\mathrm{GT})_{20}$ probe, subcloned, and sequenced (Tsukamoto et al. 1998); Sequences were determined by Dye Terminator cycle sequencing, using the 377 ABI DNA sequencer Perkin-Elmer; Norwalk, CT (DNA sequences are available through GenBank Acc no. AF141945). PCR primers were designed to flank this new repeat sequence for polymorphism analysis. 
Table 1. Size and frequencies of the 13 alleles of the CA repeat polymorphism

\begin{tabular}{lll}
\hline Allele & Size (bp) & Frequency \\
\hline A1 & 170 & 0.03 \\
A2 & 168 & 0.03 \\
A3 & 166 & 0.10 \\
A4 & 164 & 0.01 \\
A5 & 162 & 0.03 \\
A6 & 160 & 0.09 \\
A7 & 158 & 0.12 \\
A8 & 156 & 0.19 \\
A9 & 154 & 0.19 \\
A10 & 152 & 0.14 \\
A11 & 150 & 0.06 \\
A12 & 148 & 0.01 \\
A13 & 144 & 0.01 \\
\hline
\end{tabular}

PCR primers

The PCR priners used were:

Forward (SCAP-F) 5'-CAGGCTGTATAAGCTAAGTATG-3' Reverse (SCAP-R) 5'-CTGGATGTAGTGGCAGGCAC-3'

\section{PCR conditions}

PCR was performed in a volume of $10 \mu$ containing $20 \mathrm{ng}$ genomic DNA, $10 \mathrm{mM}$ Tris $\mathrm{HCl}(\mathrm{pH} 8.4), 50 \mathrm{mM} \mathrm{KCl}$, $1.5 \mathrm{mM} \mathrm{MgCl}_{2}, 0.01 \%$ of gelatin, $200 \mu \mathrm{M}$ dNTPs, $2.5 \mathrm{pmol}$ of a $\left[{ }^{32} \mathrm{P}\right]$ end-labeled forward primer and a non-labeled reverse primer, and 0.25 units of Taq polymerase. Cycle conditions were $94^{\circ} \mathrm{C}$ for $4 \mathrm{~min}$, then 35 cycles of $94^{\circ} \mathrm{C}$ for $30 \mathrm{~s}, 58^{\circ} \mathrm{C}$ for $30 \mathrm{~s}$, and $72^{\circ} \mathrm{C}$ for $30 \mathrm{~s}$, with a final extension step of $5 \mathrm{~min}$ at $72^{\circ} \mathrm{C}$ in a Gene Amp PCR9600 System (Perkin Elmer Cetus, Norwalk, CT, CA, USA). PCR products were electrophoresed in 0.3-mm-thick denaturing $6 \%$ polyacrylamide gels containing $36 \%$ formamide and $8 \mathrm{M}$ urea, at $2000 \mathrm{~V}$ for $2-4 \mathrm{~h}$. The gels were transferred to filter papers, dried at $80^{\circ} \mathrm{C}$, and autoradiographed. Sizes of the alleles were determined by comparison with the sequencing ladder of a control plasmid (Watanabe et al. 1998).
Polymorphism and allele frequency. Thirteen alleles were detected in 154 chromosomes of unrelated Japanese individuals. Observed heterozygosity was 0.89 . The sizes and frequencies of the 13 alleles are shown in Table 1.

Mendelian inheritance. Codominant inheritance was observed in two two-generation families.

Radiation hybrid mapping. The newly isolated CA repeat at the SCAP locus was mapped to chromosome $3 \mathrm{p} 21.3$, using described procedures on the G3 RH mapping panel of 83 hybrid cell lines of the Stanford Human Genome Center (Boehnke et al. 1991), by linkage to a marker SHGC-500 (D3S1322E) with a logarithm of differences (LOD) score of $>7.85$.

Acknowledgments This work was supported by Research Grants for Osteoporosis from the Ministry of Health and Welfare of Japan and the Novartis Foundation for Gerontological Research.

\section{References}

Boehnke M, Lang K, Cox DR (1991) Statistical methods for multipoint radiation mapping. Am J Hum Genet 49:1174-1188

Brown MS, Goldstein JL (1997) The SREBP pathway: regulation of cholesterol metabolism by proteolysis of a membrane-bound transcription factor. Cell 89:331-340

Hua X, Nohturfft A, Goldstein JL, Brown MS (1996) Sterol resistance in $\mathrm{CHO}$ cells traced to point mutation in SREBP cleavage-activating protein. Cell 87:415-426

Korn BS, Shimomura I, Bashmakov Y, Hammer RE, Horton JD, Goldstein JL, Brown MS (1998) Blunted feedback suppression of SREBP processing by dietary cholesterol in transgenic mice expressing sterol-resistant SCAP (D443N). J Clin Invest 102:2050-2060

Nagase T, Seki N, Ishikawa K, Tanaka A, Nomura N (1996) Prediction of the coding sequences of unidentified human genes. $\mathrm{V}$. The coding sequences of 40 new genes (KIAA0161-KIAA0200) deduced by analysis of cDNA clones from human cell line KG-1. DNA Res 3:7-24

Nohturfft A, Brown MS, Goldstein JL (1998) Sterols regulate processing of carbohydrate chains of wild-type SREBP cleavage-activating protein (SCAP), but not sterol-resistant mutants Y298C or D443N. Proc Natl Acad Sci USA 95:12848-12853

Tsukamoto K, Haruta K, Shiba T, Emi M (1998) Isolation and mapping of a polymorphic CA repeat sequence at the human interleukin 6 locus. J Hum Genet 43:71-72

Watanabe I, Tsukamoto K, Shiba T, Emi M (1998) Isolation and radiation hybrid mapping of dinucleotide repeat polymorphism at the human matrix Gla protein (MGP) locus. J Hum Genet 43:75-76 